\title{
Editorial \\ State-of-the-Art Clinical Microbiology in South Korea: Current Trends and Future Prospects
}

\author{
Garima Sharma * and Jin-Chul Kim *
}

Department of Biomedical Science \& Institute of Bioscience and Biotechnology, Kangwon National University, Chuncheon 24341, Korea

* Correspondence: microbio.garima@gmail.com (G.S.); jinkim@kangwon.ac.kr (J.-C.K.); Tel.: +82-33-250-6561 (J.-C.K.); Fax: +82-33-259-5645 (J.-C.K.)

Citation: Sharma, G.; Kim, J.-C. State-of-the-Art Clinical

Microbiology in South Korea:

Current Trends and Future Prospects.

Microorganisms 2022, 10, 174.

https://doi.org/10.3390/

microorganisms10010174

Received: 3 January 2022

Accepted: 11 January 2022

Published: 14 January 2022

Publisher's Note: MDPI stays neutral with regard to jurisdictional claims in published maps and institutional affiliations.

Copyright: (C) 2022 by the authors. Licensee MDPI, Basel, Switzerland. This article is an open access article distributed under the terms and conditions of the Creative Commons Attribution (CC BY) license (https:// creativecommons.org/licenses/by/ $4.0 /)$.
Researchers and clinicians have repeatedly explored the clinical aspects of microorganisms because the human body is inhabited by several different microbial species and their strains. The interaction between the microbial world and the human body is complicated and might lead to harmful or beneficial outcomes. On the one hand, some of the natural microbial inhabitants play an essential role in the metabolic activities of the human body [1]; alterations in the natural composition of the microbiota and various other microbial encounters influence the occurrence of infectious diseases of the gastrointestinal tract [2], urogenital tract [3], respiratory tract [4], central nervous system [5], etc. On the other hand, there has been an increase in implants or medical devices for various disease management in the past few decades. Bacterial colonization on these implants or medical devices has also severely threatened human health [6]. In the last few years, several new viral strains, such as ebola, Middle East respiratory syndrome coronavirus (MERS-CoV), and severe acute respiratory syndrome coronavirus-2 (SARS-CoV-2), etc., have been identified that have become a significant concern for public health worldwide [7]. Although, with the help of advancing technologies, the scientific community has carried out a tremendous amount of work exploring the cross-talk between the microbes and the host factors, there are still a lot of facts to uncover. Since different pathogeneses directly result from microbial infections, it is necessary to understand the relationship between the microbes and their associated health effects at the cellular and molecular levels. This would enable the development of novel antimicrobial agents. The development of antibiotic resistance by microbes is one of the biggest threats to human health [8], and thus, developing novel antimicrobial agents is the biggest challenge to the scientific community.

In 2019, the world entered a COVID-19 pandemic caused by SARS-CoV-2. Since then, various lineages (i.e., variants of concern and variants of interest) of SARS-CoV-2 have also been reported due to escape mutations [9-11]. Among all the identified variants, B.1.1.529 (Omicron) is the most recently identified strain designated as a variant of concern by the World Health Organization (WHO) $[12,13]$. COVID-19 has been associated with various clinical manifestations, such as respiratory illness, dry cough, fever, dyspnea, secondary infections, sepsis, and organ failure, which have taken millions of lives to date [14]. It is plausible that the world may face more such threats in the future due to the constant mutations and evolutions in SARS-CoV-2 or other microbes. Indeed, the human immune system responds differently to different microbial encounters. Thus, to battle the severity of newly evolving microbes, it is crucial to uncover the microbial evolution and the dynamic interplay between them and host factors. This understanding might assist in developing antimicrobial drugs and vaccines for evolutionary-related microbial infections.

Although the WHO now recommends multiple vaccines and repurposing drugs for managing the SARS-CoV-2 pandemic, their clinical efficiencies are still under trial [15]. Currently, the whole world is contributing its best efforts to develop various vaccines and drugs against COVID-19. In the attempt to combat COVID-19, 68 clinical studies 
related to drugs and vaccines against COVID-19 have been registered from South Korea in ClinicalTrials.gov (according to a search on 29 December 2021 using "COVID-19" as a keyword and "Korea, Republic of" as the country). Among them, 48 studies are either completed or are currently recruiting. Out of them, 39 studies are interventional and nine are observational, thus, signifying the efforts and current state of development of drugs and vaccines against COVID-19 in South Korea.

In view of the aforementioned, this Special Issue entitled "State-of-the-Art Clinical Microbiology in South Korea" focuses on recent advancements in the state of interactions between microbes and host factors associated with various pathogeneses. In addition, this issue also focuses on the state of the development of novel antimicrobial agents and vaccines to combat various microbial infections, including COVID-19. The contributions from leading authors from South Korea are intended to improve and expand our knowledge in the field of clinical microbiology. The planned papers are supposed to provide valuable and thought-provoking information that will give an insight into the microbe-host interactions to facilitate the development of novel antimicrobial agents and vaccines. We are honored to highlight the work of such expert groups of individuals from South Korea.

Author Contributions: Conceptualization, G.S. and J.-C.K.; writing, G.S.; supervision, J.-C.K.; funding acquisition, J.-C.K. All authors have read and agreed to the published version of the manuscript.

Funding: This research was supported by the Basic Science Research Program through the National Research Foundation of Korea (NRF), funded by the Ministry of Education (No. 2018R1A6 A1A03025582). This research was also supported by the Basic Science Research Program through the National Research Foundation of Korea (NRF) and funded by the Ministry of Education (NRF2018R1D1A1B07043439)

Conflicts of Interest: The authors declare no conflict of interest.

\section{References}

1. Ogunrinola, G.A.; Oyewale, J.O.; Oshamika, O.O.; Olasehinde, G.I. The Human Microbiome and Its Impacts on Health. Int. J. Microbiol. 2020, 2020, 8045646. [CrossRef] [PubMed]

2. Nagao-Kitamoto, H.; Kitamoto, S.; Kuffa, P.; Kamada, N. Pathogenic role of the gut microbiota in gastrointestinal diseases. Intest. Res. 2016, 14, 127-138. [CrossRef] [PubMed]

3. Perez-Carrasco, V.; Soriano-Lerma, A.; Soriano, M.; Gutiérrez-Fernández, J.; Garcia-Salcedo, J.A. Urinary Microbiome: Yin and Yang of the Urinary Tract. Front. Cell. Infect. Microbiol. 2021, 11, 421. [CrossRef] [PubMed]

4. Dickson, R.P.; Erb-Downward, J.R.; Huffnagle, G.B. The role of the bacterial microbiome in lung disease. Expert Rev. Respir. Med. 2013, 7, 245-257. [CrossRef] [PubMed]

5. Ma, Q.; Xing, C.; Long, W.; Wang, H.Y.; Liu, Q.; Wang, R.-F. Impact of microbiota on central nervous system and neurological diseases: The gut-brain axis. J. Neuroinflamm. 2019, 16, 53. [CrossRef] [PubMed]

6. von Eiff, C.; Jansen, B.; Kohnen, W.; Becker, K. Infections associated with medical devices: Pathogenesis, management and prophylaxis. Drugs 2005, 65, 179-214. [CrossRef]

7. Shinde, T.; Hansbro, P.M.; Sohal, S.S.; Dingle, P.; Eri, R.; Stanley, R. Microbiota Modulating Nutritional Approaches to Countering the Effects of Viral Respiratory Infections Including SARS-CoV-2 through Promoting Metabolic and Immune Fitness with Probiotics and Plant Bioactives. Microorganisms 2020, 8, 921. [CrossRef] [PubMed]

8. Prestinaci, F.; Pezzotti, P.; Pantosti, A. Antimicrobial resistance: A global multifaceted phenomenon. Pathog. Glob. Health 2015, 109, 309-318. [CrossRef] [PubMed]

9. Chakraborty, C.; Bhattacharya, M.; Sharma, A.R. Present variants of concern and variants of interest of severe acute respiratory syndrome coronavirus 2: Their significant mutations in S-glycoprotein, infectivity, re-infectivity, immune escape and vaccines activity. Rev. Med. Virol. 2021, e2270. [CrossRef]

10. Chakraborty, C.; Bhattacharya, M.; Sharma, A.R. Emerging mutations in the SARS-CoV-2 variants and their role in antibody escape to small molecule-based therapeutic resistance. Curr. Opin. Pharmacol. 2022, 62, 64-73. [CrossRef] [PubMed]

11. Chakraborty, C.; Sharma, A.R.; Bhattacharya, M.; Agoramoorthy, G.; Lee, S.S. Evolution, mode of transmission, and mutational landscape of newly emerging sars-cov-2 variants. MBio 2021, 12, e01140-21. [CrossRef] [PubMed]

12. Karim, S.S.A.; Karim, Q.A. Omicron SARS-CoV-2 variant: A new chapter in the COVID-19 pandemic. Lancet 2021, 398, 2126-2128. [CrossRef]

13. Thakur, V.; Ratho, R.K. OMICRON (B.1.1.529): A new SARS-CoV-2 variant of concern mounting worldwide fear. J. Med. Virol. 2021. [CrossRef] [PubMed] 
14. da Rosa Mesquita, R.; Francelino Silva Junior, L.C.; Santos Santana, F.M.; Farias de Oliveira, T.; Campos Alcântara, R.; Monteiro Arnozo, G.; Rodrigues da Silva Filho, E.; Galdino Dos Santos, A.G.; Oliveira da Cunha, E.J.; Salgueiro de Aquino, S.H.; et al. Clinical manifestations of COVID-19 in the general population: Systematic review. Wien. Klin. Wochenschr. 2021, 133, 377-382. [CrossRef] [PubMed]

15. Pan, H.; Peto, R.; Henao-Restrepo, A.-M.; Preziosi, M.-P.; Sathiyamoorthy, V.; Abdool Karim, Q.; Alejandria, M.M.; Hernández García, C.; Kieny, M.-P.; Malekzadeh, R.; et al. Repurposed Antiviral Drugs for Covid-19-Interim WHO Solidarity Trial Results. N. Engl. J. Med. 2021, 384, 497-511. [CrossRef] [PubMed] 